\title{
Development of a three-parameter model of the shoe brake contact interaction with the drum in mine hoisting machine
}

\author{
Kostiantyn Zabolotnyi ${ }^{1}$, Oleksand Zhupiiev ${ }^{1}$, and Artur Molodchenko ${ }^{1 *}$ \\ ${ }^{1}$ National Mining University, Mining Machines \& Engineering Department, 19 Yavornytskoho Ave., \\ 49005 Dnipro, Ukraine
}

\begin{abstract}
For safe operation of mine hoisting machines (MHM) in the mining industry, it is necessary to provide high constructive reliability of brake systems, in particular, brake systems based on the block brake. The contact interaction of the brake with the translational movement of the shoes applied in MHM, remains insufficiently studied. In particular, it is necessary to develop a technique for accurate determination of the braking moment and forces in the elements of the brake linkage, as well as to study the nature of the pressure distribution along the brake beam. The purpose of this article is to simulate the contact interaction of the MHM brake taking into account the coefficient of friction, the ratio of the flexural stiffness to the longitudinal stiffness of a beam, as well as the ratio of the transverse stiffness of a lining to the flexural stiffness of a beam. The application of the developed model will help to reduce the maximum contact pressure in the shoe brakes of the mine hoisting machines and will allow more accurate calculation of the braking moment value compared to existing methods.
\end{abstract}

\section{Introduction}

The hoists are considered to be the most important installation among all the machinery used in the mining industry. An emergency situation in the process of the hoisting machine operation actually stops all the mining works in the mine, which leads to huge financial losses. This determines the high requirements to the technical level of mine hoisting machines and the quality of their manufacturing.

Novokramatorskyi Mashynobudivnyi Zavod (NKMZ), one of the largest production and research complexes in Europe, up to now produces drum-type hoisting machines, which are often equipped with shoe brakes. A lot of well-known scientists have been involved into the designing of the braking device for MHM, but because of the imperfection of the previously used computing facilities, the very important parameters for the interaction

\footnotetext{
${ }^{*}$ Corresponding author: artamaranth0.0@gmail.com
} 
between the brake beam, lining and the brake rim, have not been studied. For example, the problem of calculating the brakes of mine hoisting machines has recently been considered by Barecki Z. and Sciezska S.F. [1]. However, in their mathematical model of the contact interaction between the brake shoe and the drum, they did not take into account the influence of tangential forces on the distribution of the contact pressure, and the calculation given as an example concerns a particular machine without specifying brake parameters, in addition, the article published on this topic does not contain any generalized dependences.

To calculate the braking parameters for large hoisting machines produced by the NKMZ with the translational movement of the brake shoes, the method described in the works of Davydov B.L., Karpyshev N.S., and Fedorova Z.M. has been used so far. Here, a hypothesis is made about the sinusoidal law of contact pressures distribution, which is consistent with the assumption of the absolute stiffness of the brake beam $[3,7,10]$.

The traditional mathematical model of Davydov B.L. for calculating the distributed tangential and normal forces acting on the brake beam of the MHM shoe brake is based on the assumption that these forces are distributed independently of the lining friction against the drum and the flexural stiffness of the beam. This assumption cannot be considered valid, and therefore the results of determining the specified loads in the construction of a shoe brake can lead to significant errors and the creation of further emergency situations.

The results of the computational experiment carried out by means of the SolidWorks Simulation Program on the study of a shoe brake for the CR-4x3/0.7 type mine hoisting machine with translationally moving shoes, make it possible to construct a U-shaped pressure distribution curve.

Many researchers of contact interaction of shoe brakes with a drum, in particular, Day A.J., Newcomb T.P., Harding P.R., Huang YU.M., Shyr J.S., Tirovic M., Barecki Z. and Sciezska S.F., using in their works the method of finite elements, finite-difference method and the boundary element method, have proved the invalidity of the hypothesis about absolute stiffness of a beam.

The calculations, given in works of Day A.J., with the use of the finite elements method relate to the specific case where the brake beam is modeled as a sequence of beams with different cross sections [4-6].

In the calculations of Huang Y.M. and Shir J.S. the boundary element method was used without analysis of the basic parameters influencing the contact interaction [8].

In the works of Zabolotnyi K.S., Kolosov D.L., Moskalova T.V. the techniques were described for the construction optimization of drums and brakes in the mine hoisting machines by determining the stress-strain state [11, 15, 17-20].

In further numerous works on improving the calculation technique for brakes, the dynamic and thermal processes were taken into account which proceed in the braking system elements. For example, in the works of Kyrychenko Y.O., Samusia V. I., Ilyn S.R. and Bondarenko V.I., the problems of hoisting plant dynamics during working and safety braking was considered. Most importantly, that the hypothesis of stiffness of the brake rim and beam, was not substantiated $[2,9,12-14,16]$.

\section{Development of a three-parameter model of contact interaction}

Fig. 1 shows the scheme of a part of the braking system for large-size MHM produced by NKMZ. By means of the brake linkage, the braking force is transferred to the upper 4 and lower 5 rods. The center of the brake beam rotates on a vertical pillar 3 . The brake shoe consists of a brake beam 1 and a set of linings 2 . These linings interact with the drum 6 during braking. Thus, it can be assumed that the brake shoe is affected by two couplings: a vertical pillar and a drum. 
The exact calculation of the forces arising in the brake shoe is possible only with the use of numerical methods (the methods of finite or boundary elements), but in order to reveal the basic laws of contact interaction, it is required to create a simplified analytical model of a structure. It has been decided to represent it in the form of a circular bar with the constant cross section, fixed from vertical displacements in the central point. According to the accepted assumption, the same external forces act on the bar in the horizontal rods.

The physical model of the brake lining has been defined as an array of elastic bodies, like Winkler foundation, which do not interact with each other, work in compression and transfer the distributed frictional forces arising between the brake drum and the brake shoe, calculated for the limited equilibrium state in accordance with Coulomb's law (Fig. 2).

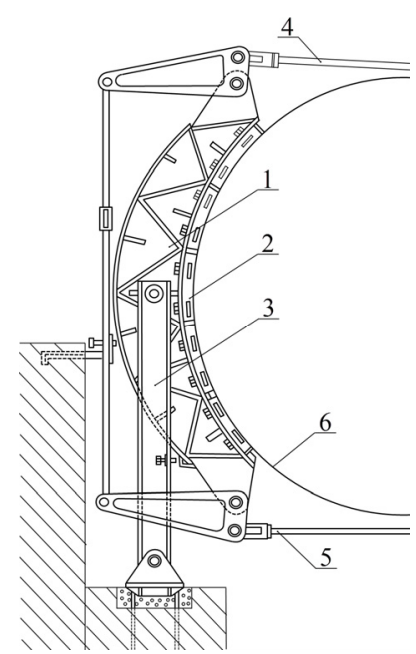

Fig. 1. Scheme of a part of the MHM brake system.

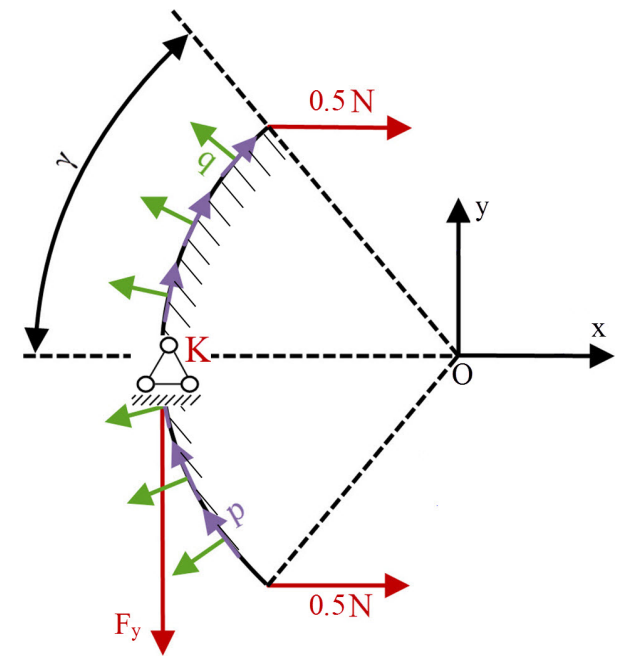

Fig. 2. Scheme of the forces arising in the brake beam.

The condition has also been accepted that the drum rotates clockwise, and the angle of wrap of the brake shoe is equal to $2 \gamma$. Having replaced the couplings on reactions, we determine the concentrated vertical force $F_{y}$ in the central point of the bar, as well as the distributed forces $q$ and $p$ of the drum action on the lining. In view of small thickness of the beam, we consider that these forces are applied to the neutral axis of the bar.

The action of the horizontal movable bearing in the brake system causes the occurrence of a force jump (vertical reaction of the bearing), which ensures the discontinuity of the longitudinal force function, excluding the possibility to consider the bar as an element of structural mechanics. Therefore, in the model for calculation, it is provided that the bar consists of two parts: the upper and lower ones.

The mathematical model for calculation of forces in the brake shoe includes the number of the equations presented below.

Equilibrium equations for the lower $(i=0)$ and upper $(i=1)$ parts of the bar have the following form:

$$
\frac{d Y_{i}}{d \varphi}=A_{i} Y_{i}
$$


where $Y_{i, 1} \equiv T_{i}, Y_{i, 2} \equiv Q_{i}, Y_{i, 3} \equiv M_{i}, A_{i} \equiv\left[\begin{array}{c}Y_{i, 2}+p_{i} R \\ -Y_{i, 1}+q_{i} R \\ Y_{i, 2} R\end{array}\right], T_{i}(\varphi)$ is the longitudinal force; $Q_{i}(\varphi)$ is the shear force; $M_{i}(\varphi)$ is the bending moment; $\varphi$ is the current angular coordinate; $R$ is the radius of the neutral line of the brake beam.

The equation for calculating the distributed normal forces that correspond to the model of a structure with an elastic base, can be represented as follows:

$$
q_{i}(\varphi)=\kappa w_{i}(\varphi) ; \quad(i=0,1),
$$

where $w_{i}$ ( $\varphi$ is the depth of beam deflection; $E_{l}$ is the elasticity modulus of the lining material; $H_{l}$ is the thickness of the lining; $B_{b}$ is the width of the brake field; $\kappa$ is the transverse stiffness of the lining, defined by the following expression:

$$
\kappa=E_{l} \frac{B_{b}}{H_{l}} .
$$

The equation describing the distributed friction force according to Coulomb's law has the following form:

$$
p_{i}(\varphi)=f \kappa w_{i}(\varphi) ; \quad(i=0,1) .
$$

We formulate Hooke's law for determining the bending moment, that is

$$
M_{i}(\varphi)=-\frac{E I}{R} \frac{d \theta_{i}(\varphi)}{d \varphi} ; \quad(i=0,1) .
$$

where $E$ is the elasticity modulus of the beam material; $I$ is the inertia moment of the beam section; $\theta_{i}$ is the angle of the beam rotation.

Here we take into account the following kinematic dependence:

$$
\theta_{i}(\varphi)=\frac{1}{R}\left(\frac{d w_{i}(\varphi)}{d \varphi}+v_{i}(\varphi)\right) ; \quad(i=0,1),
$$

and Hooke's law for determining the longitudinal tension, that is

$$
T_{i}(\varphi)=\frac{E F}{R}\left(\frac{d v_{i}(\varphi)}{d \varphi}-w_{i}(\varphi)\right) .
$$

where $F$ is the cross-sectional area of the beam.

Both bars are connected in a place designated in the scheme by the point $K$, in which the value $\varphi=0$, they are fixed there from vertical displacements. Thus, the state of the construction corresponds to the following dependences:

$$
\begin{array}{ccc}
v_{0}(0)=0 ; & v_{1}(0)=0 ; & w_{0}(0)=w_{1}(0) ; \\
\theta_{0}(0)=\theta_{1}(0) ; & M_{0}(0)=M_{1}(0) ; & Q_{0}(0)=Q_{1}(0) .
\end{array}
$$

At the upper and lower ends of each beam, zero values of the bending moments are set, as well as the tangential and radial components of the horizontal forces in the rods, that is 


$$
\begin{array}{cc}
T_{0}(-\gamma)=0.5 N \sin (\gamma) ; & T_{1}(\gamma)=0.5 N \sin (\gamma) ; \\
M_{0}(-\gamma)=0 ; & M_{1}(\gamma)=0 ; \\
Q_{0}(-\gamma)=0.5 N \cos (\gamma) ; & Q_{1}(\gamma)=-0.5 N \cos (\gamma) .
\end{array}
$$

Now we turn to the determination of dimensionless quantities, namely:

$$
\begin{gathered}
v_{i}^{*}=\frac{v_{i}}{\mu R} ; \\
w_{i}^{*}=\frac{w_{i}}{\mu R} ; \\
\theta_{i}^{*}=\frac{\theta_{i}}{\mu} ; \\
T_{i}^{*}=\frac{T_{i}}{\mu E F} ; \\
M_{i}^{*}=\frac{R M_{i}}{\mu E I} ; \\
Q_{i}^{*}=\frac{R^{2} Q_{i}}{\mu E I},
\end{gathered}
$$

where $\mu=\frac{0.5 N}{E F}$ is a multiplier factor proportional to the applied force.

To reduce the volume of the record, we transform the listed expressions into a vectormatrix form.

The vector of undetermined values is a transposed line, that is:

$$
y_{i}=\left(\begin{array}{llllll}
v_{i}^{*} & w_{i}^{*} & \theta_{i} * T_{i}^{*} & M_{i} * Q_{i}^{*}
\end{array}\right)^{T} .
$$

Then the equation corresponding to the mathematical model will be as follows:

$$
\frac{d y_{i}}{d \varphi}=A y_{i},
$$

where

$$
A=\left(\begin{array}{cccccc}
0 & 1 & 0 & 1 & 0 & 0 \\
-1 & 0 & 1 & 0 & 0 & 0 \\
0 & 0 & 0 & 0 & -1 & 0 \\
0 & -f \lambda \zeta & 0 & 0 & 0 & -\zeta \\
0 & 0 & 0 & 0 & 0 & -1 \\
0 & -\lambda & 0 & \frac{1}{\zeta} & 0 & 0
\end{array}\right)
$$

where $\lambda$ is the relative transverse stiffness, defined as follows:

$$
\lambda=\frac{\kappa R^{4}}{E I},
$$


$\zeta$ is the relative flexural stiffness, which is calculated by the following formula:

$$
\zeta=\frac{E I}{E F R^{2}}
$$

To solve the formulated system of linear differential equations with constant values of the coefficients, Euler's method is used. When used for the MHM braking system, the following dependences are valid:

$$
\begin{array}{cc}
n_{0}=\alpha_{0}+i \beta_{0} ; & n_{1}=\alpha_{0}-i \beta_{0} ; \\
n_{2}=\alpha_{1}+i \beta_{1} ; & n_{3}=\alpha_{1}-i \beta_{1} ; \\
n_{4}=0 ; & n_{5}=p_{i}(\varphi) ; \\
z_{0}(\varphi)=\exp \left(\alpha_{0} \varphi\right)\left[\operatorname{Re}\left(\Phi^{\langle 0\rangle}\right) \cos \left(\beta_{0} t\right) \varphi-\operatorname{Im}\left(\Phi^{\langle 0\rangle}\right) \sin \left(\beta_{0} \varphi\right)\right] \\
z_{1}(\varphi)=\exp \left(\alpha_{0} \varphi\right)\left[\operatorname{Re}\left(\Phi^{\langle 0\rangle}\right) \sin \left(\beta_{0} \varphi\right)+\operatorname{Im}\left(\Phi^{\langle 0\rangle}\right) \cos \left(\beta_{0} \varphi\right)\right] \\
z_{2}(\varphi)=\exp \left(\alpha_{1} \varphi\right)\left[\operatorname{Re}\left(\Phi^{\langle 2\rangle}\right) \cos \left(\beta_{1} \varphi\right)-\operatorname{Im}\left(\Phi^{\langle 2\rangle}\right) \sin \left(\beta_{1} \varphi\right)\right] \\
z_{3}(\varphi)=\exp \left(\alpha_{1} \varphi\right)\left[\operatorname{Re}\left(\Phi^{\langle 2\rangle}\right) \sin \left(\beta_{1} \varphi\right)+\operatorname{Im}\left(\Phi^{\langle 2\rangle}\right) \cos \left(\beta_{1} \varphi\right)\right] \\
z_{4}(\varphi)=\frac{\Phi^{\langle 4\rangle}}{\left(\Phi^{\langle 4\rangle}\right)_{0}} ; \\
z_{5}(\varphi)=\exp (\tau \varphi) \frac{\Phi^{\langle 5\rangle}}{\left(\Phi^{\langle 5\rangle}\right)_{0}}
\end{array}
$$

where $n$ is the eigenvalues of the matrix $A$; $\Phi$ is the eigenvectors of the matrix $A$.

If the coefficient of friction is zero, then the zero root becomes reiterated, namely:

$$
n_{5}=0 \text {. }
$$

This makes it necessary to find out the eigenfunction as a linear one, that is

$$
\begin{aligned}
& y(\varphi)=C+D \varphi ; \quad D=A(C+D \varphi) ; D=A C ; \quad A D=0 ; \\
& D=(1, \quad 0, \quad 1, \quad 0, \quad 0, \quad 0)^{T}
\end{aligned}
$$

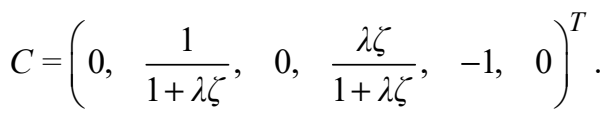

In this case

$$
\begin{gathered}
z_{4}(\varphi)=D ; \\
z_{5}(\varphi)=C+D \varphi .
\end{gathered}
$$

The solution of the differential equations system corresponds to a linear combination of fundamental functions with undetermined values of the coefficients, that is 


$$
y_{i}(\varphi)=\sum_{k=0}^{5}\left[S_{6 i+k}\left(z(\varphi)_{k}\right)\right] ; \quad(i=0,1)
$$

To determine these coefficients, the boundary conditions given below (Table 1) are used. These conditions are assigned in the form of the following system of algebraic equations:

$$
G S=B
$$

To calculate the coefficient values, the function $S=$ lsolve $(G, B)$ built into the MathCAD program is used.

We designate the ratio of the contact pressure to the pressure caused by the same force $N$ acting on an absolutely rigid section of the same area $(F=B R 2 \gamma)$ by the adjusted pressure value $\Xi$. We denote by $\chi$ its maximum value.

Table 1. Boundary conditions of the mathematical model for determining the forces acting on the brake beam.

\begin{tabular}{|c|c|}
\hline Boundary conditions & Physical meaning \\
\hline$G_{0, k}=\left[z(0)_{k}\right]_{0}$ & $v_{0}(0)=0$ \\
\hline$G_{1, k+6}=\left[z(0)_{k}\right]_{0}$ & $v_{1}(0)=0$ \\
\hline$G_{2, k}=\left[z(0)_{k}\right]_{1} ; G_{2, k+6}=-\left[z(0)_{k}\right]_{1}$ & $w_{0}(0)=w_{1}(0)$ \\
\hline$G_{3, k}=\left[z(0)_{k}\right]_{2} ; G_{3, k+6}=-\left[z(0)_{k}\right]_{2}$ & $\theta_{0}(0)=\theta_{1}(0)$ \\
\hline$G_{4, k}=\left[z(0)_{k}\right]_{4} ; G_{4, k+6}=-\left[z(0)_{k}\right]_{4}$ & $M_{0}(0)=M_{1}(0)$ \\
\hline$G_{5, k}=\left[z(0)_{k}\right]_{5} ; G_{5, k+6}=-\left[z(0)_{k}\right]_{5}$ & $Q_{0}(0)=Q_{1}(0)$ \\
\hline$G_{6, k}=\left[z(-\gamma)_{k}\right]_{3} ; B_{6}=\sin (\gamma)$ & $T_{0}(-\gamma)=0.5 N \sin (\gamma)$ \\
\hline$G_{7, k}=\left[z(\gamma)_{k}\right]_{3} ; B_{7}=\sin (\gamma)$ & $T_{1}(\gamma)=0.5 N \sin (\gamma)$ \\
\hline$G_{8, k}=\left[z(-\gamma)_{k}\right]_{4}$ & $M_{0}(-\gamma)=0$ \\
\hline$G_{9, k+6}=\left[z(\gamma)_{k}\right]_{4}$ & $M_{1}(\gamma)=0$ \\
\hline$G_{10, k}=\left[z(-\gamma)_{k}\right]_{5} ; B_{10}=\frac{\cos (\gamma)}{\zeta}$ & $Q_{0}(-\gamma)=0.5 N \cos (\gamma)$ \\
\hline$G_{11, k+6}=\left[z(\gamma)_{k}\right]_{5} ; B_{11}=-\frac{\cos (\gamma)}{\zeta}$ & $Q_{1}(\gamma)=-0.5 N \cos (\gamma)$ \\
\hline
\end{tabular}

Fig. 3 shows the distribution curves of the adjusted values of the contact pressure according to different values of the parameters $\lambda$ and $\zeta$. Here we see that the parameter $\zeta$ influences the pressure distribution only in case when $\lambda>100$. The nature of the distribution depends essentially on the relative transverse stiffness of the structure. Thus, if $\lambda>10$, then the distribution curve has a U-shaped form with a clear-cut edge effect, but in case of $\lambda$ value increasing it becomes asymmetric. When $\lambda \leq 10$, the character of the curve is sinusoidal, according to which the maximum values of the contact pressure are observed in the center of the brake shoe. Close distribution to the uniform distribution of contact pressures, taking into 
account the considered values of the parameter $\zeta$ occurs if $\lambda \approx 10$. Neglect of the frictional forces when calculating the distribution of the contact pressure leads in the sequel to an error of the obtained maximum pressure values of $1.3 \%$, if $\zeta=0.002$, and $11 \%$ when $\zeta=0.07$.

In order to consider both types of distribution, we use the above described adjusted maximum value of the contact pressure $\Xi$. Since in Fig. 3 the adjusted values of the contact pressure in specific points are indicated, and the value of the parameter $\lambda$ exceeds the value of the parameter $\zeta$, we plot the graph of the maximum pressure dependence as a continuous function $\lambda$ (Fig. 4).
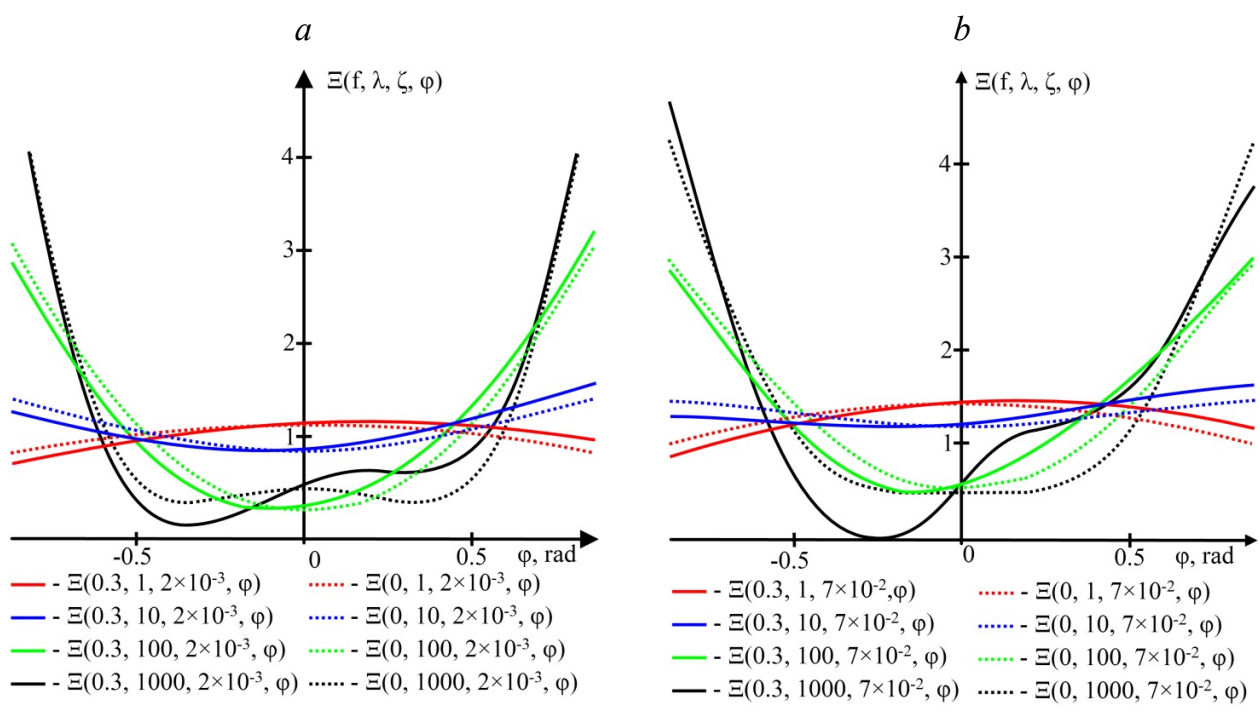

Fig. 3. The distribution curves of contact pressure values along the arc of the brake shoe: $a-\zeta=0.002, b-\zeta=0.07$.

$a$

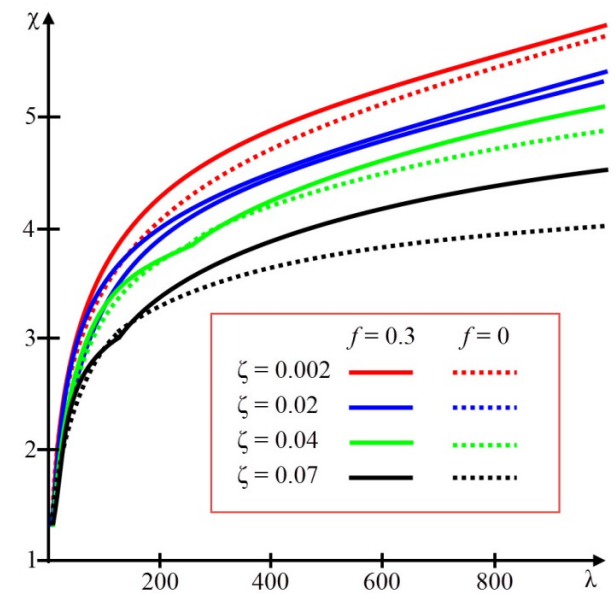

$b$

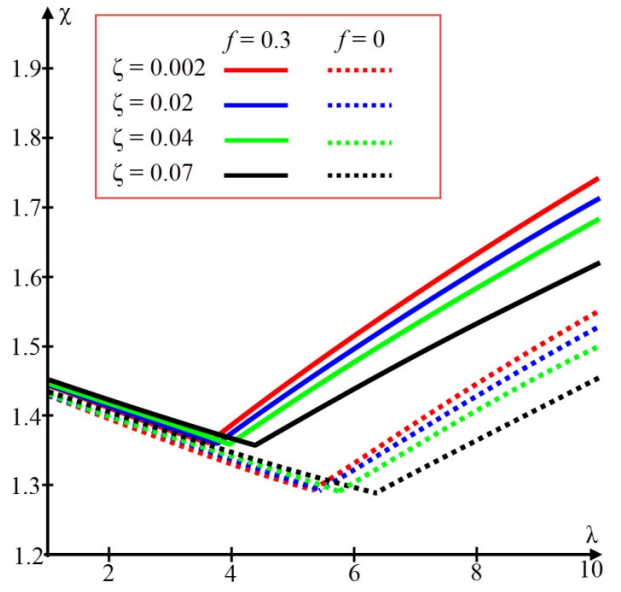

Fig. 4. Graph of the maximum contact pressure dependence on the relative transverse stiffness, at various values of the parameter $\zeta: a$-the general graph view, $b$ - the enlarged fragment of the graph.

As follows from the data in Fig. 4 , in the range of the parameter $\lambda>4$ values, the dependence of the maximum contact pressure on the relative transverse stiffness is a 
monotone function with a decreasing angle of its curve slope, which corresponds to the edge effect of the U-shaped distribution curve. If the values of the parameter $\lambda<4$ (which corresponds to the central part of the sinusoidal curve), then this dependence is a monotonically decreasing function, close to the linear one.

In Fig. 5, for greater clearness, the curves of the level of contact pressure maxima are shown, depending on different values of the relative transverse stiffness and the relative longitudinal stiffness of the structure (dashed lines indicate the level curves reflecting the values, which were calculated without considering the influence of friction forces on the contact pressure distribution).

As the data analysis in Fig. 5 has shown, if the value of the parameter $\lambda<150$, then the curves are close to vertical straight lines and reflect insignificantly the dependence on the $\zeta$ values. With an increase in the value of the parameter $\lambda$, they acquire a parabolic shape, and at $\lambda>800$, they show the dependence close to a straight line at an angle of $45^{\circ}$.

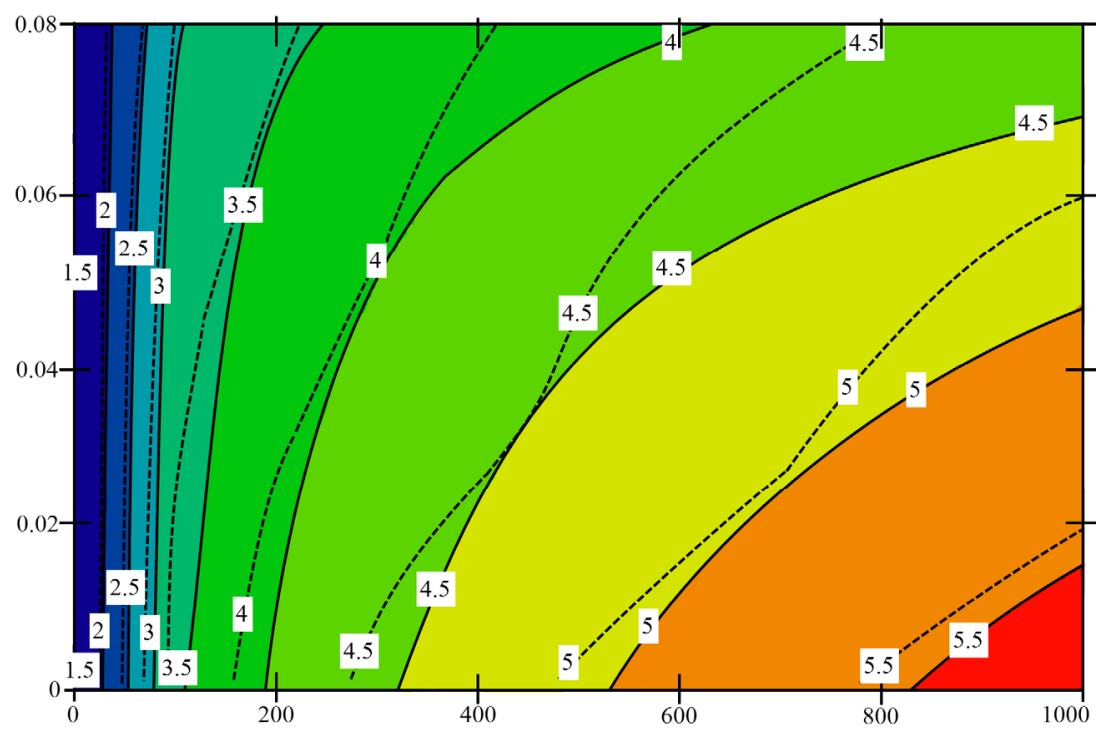

Fig. 5. The level curves of the adjusted contact pressure maxima depending on different $\lambda$ and $\zeta$ parameters values.

To carry out the numerical experiment, the characteristics of the brake beam of the CR$4 \times 3 / 0.7$ machine with the following parameters have been chosen:

- radius of the neutral line of the brake beam $R=2.26 \mathrm{~mm}$;

- width of the brake field $B_{l}=400 \mathrm{~mm}$;

- half of the grip hold arc of the brake drum $\gamma=50^{\circ}$;

- thickness of the brake beam $H=400 \mathrm{~mm}$;

- thickness of the lining $H_{l}=80 \mathrm{~mm}$;

- elasticity modulus of the beam material $E=2.1 \cdot 10^{11} \mathrm{~Pa}$;

- elasticity modulus of the lining material $E_{l}=3 \cdot 10^{8} \mathrm{~Pa}$;

- coefficient of friction $f=0,0.3$;

- relative stiffness of the brake beam $\lambda=109.4$;

- relative flexural stiffness of the brake beam $\xi=2.61 \cdot 10^{-3}$.

The graph of the contact pressure calculation results is shown in Fig. 6, where the red 
color indicates the curve reflecting the calculation by the model without consideration of the effect of friction on the contact pressure distribution (hereinafter 'without friction'), the blue color - the curve with account of frictional forces and the green color indicates the curve constructed by calculations using the model of Davydov B.L.

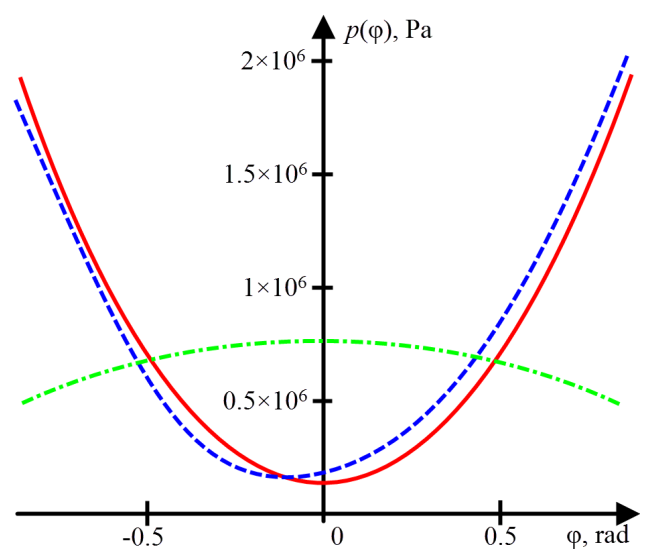

Fig. 6. Graph of the contact pressure values distribution along the arc of the brake beam.

Having transformed the equations describing the distributed normal forces in the beam, we obtain the following dependences:

- braking moment:

$$
M_{b}=f B_{b} R^{2} \int_{-\gamma}^{\gamma} q(\varphi) d \varphi ;
$$

- total force in the horizontal rods:

$$
N_{x}=B_{b} R \int_{-\gamma}^{\gamma} q(\varphi) \cos (\varphi) d \varphi ;
$$

- force in the vertical pillar:

$$
N_{y}=B_{b} R \int_{-\gamma}^{\gamma} q(\varphi) \sin (\varphi) d \varphi .
$$

The force value in the horizontal rods applied to this machine is $699 \mathrm{kN}$, used in the calculations based on the model of Davydov B.L. [3].

Then the braking moment calculated with the use of 'no friction' model is equal to $7.72 \cdot 10^{5} \mathrm{~N} \cdot \mathrm{m}$, with account of friction $-7.87 \cdot 10^{5} \mathrm{~N} \cdot \mathrm{m}$, but the braking moment calculated by the model of Davydov B.L. $-6.98 \cdot 10^{5} \mathrm{~N} \cdot \mathrm{m}$.

The deviation of this parameter value towards the decrease when calculating with the use of simplified model is $1.94 \%$, but in the calculations by the model of Davydov B.L. $11.3 \%$.

As in the previous case of the mentioned models use, the force in the vertical pillar has the following values: $2.75 \cdot 10^{5} \mathrm{~N} ; 3.48 \cdot 10^{5} \mathrm{~N} ; 2.75 \cdot 10^{5} \mathrm{~N}$ respectively. The error in determining this indicator with the use of both models, simplified and Davydov B.L., is $26.5 \%$. 


\section{Conclusions}

For the first time, a physical model of the MHM brake shoe has been developed, in which the linings are modeled as an array of elastic bodies like Winkler foundation. These bodies work in compression and transfer the distributed tangential load (frictional force) arising between the brake drum and the brake shoe; the load is calculated for the ultimate equilibrium state in accordance with Coulomb's law; and the brake beam is represented as a circular bar with a constant cross-section, which has the finite tensile stiffness, the bar is mounted on a vertical pillar and interacts with the brake drum through the brake lining loaded with a distributed normal and tangential load, which simulates the contact interaction of the brake shoe and the drum; at the same time, the vertical pillar has been modeled as a movable hinge pivot located in the middle of the circular bar.

For the first time, a three-parameter mathematical model for the determination of the tangential and normal forces acting on the brake beam has been developed, in which the flexural stiffness and tensile stiffness of the beam, as well as the transverse stiffness of the lining under the influence of different friction forces values on the contact pressure distribution, have been taken into account. The model contains six equilibrium equations for the elementary sections of a circular bar on an elastic foundation, which are under the action of distributed friction forces, calculated according to Coulomb's law; equations describing Hooke's law as applied to the bending moment and longitudinal force; twelve boundary conditions for determining the values of the cutting and longitudinal force, the bending moment along the bar edges, the continuity of all displacements and forces, with exception of the longitudinal one; while the longitudinal displacement in the place of setting the movable hinge pivot is equal to zero.

By the method of solving the problem of finding the eigenvalues, the dimensionless quantities of all variables and forces in the form of linear combinations of eigenfunctions have been determined. Using a linear system of equations for coefficients determination of these combinations obtained with account of the boundary conditions, we have formulated the system of linear equations and calculated the contact pressure, the braking moment, the forces in the rods and in the pillar.

For the first time, the dependences of the adjusted maximum pressure value on the relative transverse stiffness of the brake lining and the relative longitudinal stiffness of the brake beam have been established.

The most uniform distribution of the contact pressure is achieved in the range of variation of the relative transverse stiffness of the beam from 1 to 10 . At lower values of this parameter, the nature of the distribution curve has a sinusoidal form when the maximum values of the contact pressure are observed in the center of the brake shoe, and the higher values are distributed along the U-shaped curve with a clear-cut edge effect. Neglect of the frictional forces when calculating the distribution of the contact pressure causes an error in calculation of the maximum pressure value equal to $1.3 \%$, with a relative flexural stiffness of 0.002 and $11 \%$ when the relative flexural stiffness is 0.07 .

If the values of the relative transverse stiffness are below 150, the curves of the maximum pressure level are close to vertical straight lines and reflect insignificantly the dependence on the values of the relative flexural stiffness. With an increase in the relative transverse stiffness parameter, the curves acquire a parabolic shape, while when the relative transverse stiffness exceeds 800, the curves of this dependence are close to straight lines at an angle of $45^{\circ}$.

By the example of the shoe brake operation of the CR-4x3/0.7 mine hoisting machine, it has been proved that the distribution of the contact pressure acting upon the brake beam, which is calculated by the method of Davydov B.L. and obtained with the use of proprietary technology, has a fundamental difference: in the first case of the given distribution - a sinusoidal, and in the second case, stated in this work, it is a U-shaped parabola with a clear- 
cut edge effect. In this case, the value of the maximum contact pressure, calculated by the model of Davydov B.L., has turned out to be by 2.5 times lower.

The error in the braking moment determination with the application of the model of Davydov B.L. is $11.3 \%$, and the efforts in the vertical pillar is $26.5 \%$.

Authors express gratitude to Yurii Ovchynnikov, the Lead Designer of the Novokramatorskyi Mashynobudivnyi Zavod for providing help and consultations during the work performance.

\section{References}

1. Barecki, Z., \& Scieszka, S.F. (1987). A Mathematical Model of the Brake Shoe and the Brake Path System. N\&O JOERNAAL, 13-17. http://dx.doi.org/10.1115/1.3258977

2. Bondarenko, V.I., Samusya, V.I., \& Smolanov, S.N. (2005). Mobile lifting units for wrecking works in pit shafts. Gornyi Zhurnal, 99-100.

3. Davydov, B.L. (1949). Raschet i konstruirovanie shakhtnykh pod'yemnykh mashin. Moskva: Ugletekhizdat.

4. Day, A.J. (1991). Drum brake interface pressure distributions. Proc Instn Mech Engrs, 127-135. http://dx.doi.org/10.1243/PIME_PROC_1991_205_161_02

5. Day, A.J., Harding, P.J., \& Newcomb, T.P. (1979). A finite element approach to drum brake analysis. Proceedings of the Institution of Mechanical Engineers, (193), 400-406. http://dx.doi.org/10.1243/PIME_PROC_1979_193_043_02

6. Day, A.J., Tirovic, M., \& Newcomb, T.P. (1991). Thermal effects and pressure distributions in brakes. Proceedings of the Institution of Mechanical Engineers, (205), 199-205. http://dx.doi.org/10.1243/PIME PROC 199120517102

7. Fedorova, Z.M. (1961). Sbornik primerov i zadach po rudnichnym pod'yemnym ustanovkam. Moskva: Gosudarstvennoe nauchno-tekhnicheskoe izdatel'stvo literatury po gornomu delu.

8. Huang, Y.M., \& Shyr, J.S. (2002). On Pressure Distributions of Drum Brakes. Journal of Mechanical Design, (124), 115-120. http://dx.doi.org/10.1115/1.1427694

9. Ilin, S.R., Samusia, V.I., Ilina, I.S., \& Ilina, S.S. (2016). Influence of dynamic processes in mine hoists on safety exploitation of shafts with broken geometry. Naukovyi Visnyk Natsionalnoho Hirnychoho Universitetu, (3), 42-47.

10. Karpyshev, N.S. (1968). Tormoznye ustroystva shakhtnykh pod'yemnykh mashin. Moskva: Nedra.

11. Kolosov, D., Dolgov, O., \& Kolosov, A. (2013). The stress-strain state of the belt on a drum under compression by flat plates. Annual Scientific-Technical Collection - Mining of Mineral Deposits, 351-357. http://dx.doi.org/10.1201/b16354-65

12. Kyrychenko, Y.O., Samusia, V.I., \& Kyrychenko, V.Y. (2012). Software development for the automatic control system of deep water hydrohoist. Geomechanical Processes During Underground Mining: School of Underground Mining 2012, 81-86. http://dx.doi.org/10.1201/b13157-14

13. Kyrychenko, Y.O., Samusia, V.I., Kyrychenko, V.Y., \& Goman, O. (2012). Experimental investigation of aeroelastic and hydroelastic instability parameters of a marine pipeline. Geomechanical Processes During Underground Mining: School of Underground Mining 2012, 163167. https://doi.org/10.1201/b13157-28

14. Kyrychenko, Y.O., Samusya, V.I., Kyrychenko, V.Y., \& Romanyukov, A.V. (2013). Experimental investigation of aero-hydroelastic instability parameters of the deepwater hydrohoist pipeline. Middle East Journal of Scientific Research, 530-534. http://dx.doi.org/10.5829/idosi.mejsr.2013.18.4.12426

15. Moskalyova, T.V., \& Polushyna, M.V. (2015). Cross way of fastening steel ropes to a singledrum mine hoisting plant with the location of pulleys on the same axis. Naukovyi Visnyk Natsionalnoho Hirnychoho Universitetu, 56-62.

16. Samusia, V.I., Oksen, Y.I., \& Radiuk, M.V. (2013). Heat pumps for mine water waste heat recovery. Annual Scientific-Technical Collection - Mining of Mineral Deposits, 153-157. 
http://dx.doi.org/10.1201/b16354-27

17. Zabolotny, K., \& Panchenko, E. (2010). Definition of rating loading in spires of multilayer winding of rubberrope cable. New Techniques and Technologies in Mining, 223-229. https://doi.org/10.1201/b11329-38

18. Zabolotny, K., Zhupiev, O., \& Molodchenko, A. (2015). Analysis of current trends development of mining hoist design engineering. Theoretical and Practical Solutions of Mineral Resources Mining, 175-178. https://doi.org/10.1201/b19901-32

19. Zabolotnyi, K., Zhupiiev, O., \& Molodchenko, A. (2017). Development of a model of contact shoe brake-drum interaction in the context of a mine hoisting machine. Mining of Mineral Deposits, 11(4), 38-45. https://doi.org/10.15407/mining11.04.038

20. Zabolotnyi, K., Zhupiiev, O., \& Molodchenko, A. (2018). The effect of stiffness of shoe brake elements on the distribution of contact pressures. Naukovyi Visnyk Natsionalnoho Hirnychoho Universitetu, 2(164), 39-46. 